\title{
Reassessing the role of high dose cytarabine and mitoxantrone in relapsed/refractory acute myeloid leukemia
}

\author{
Jonathan Canaani $^{1}$, Meital Nagar ${ }^{1}$, Gabriel Heering ${ }^{1}$, Chen Gefen ${ }^{1}$, Ronit \\ Yerushalmi $^{1}$, Noga Shem-Tov ${ }^{1}$, Yulia Volchek ${ }^{1}$, Drorit Merkel ${ }^{1}$, Abraham Avigdor ${ }^{1}$, \\ Avichai Shimoni ${ }^{1}$, Ninette Amariglio ${ }^{1}$, Gidi Rechavi $^{1}$ and Arnon Nagler ${ }^{1}$ \\ ${ }^{1}$ Hematology Division, Chaim Sheba Medical Center, Tel Aviv University, Tel Aviv, Israel \\ Correspondence to: Arnon Nagler, email: Arnon.nagler@sheba.health.gov.il \\ Keywords: acute myeloid leukemia; FLT3-ITD; next-generation sequencing
}

Received: January 30, $2020 \quad$ Accepted: May 14, $2020 \quad$ Published: June 09, 2020

Copyright: Canaani et al. This is an open-access article distributed under the terms of the Creative Commons Attribution License 3.0 (CC BY 3.0), which permits unrestricted use, distribution, and reproduction in any medium, provided the original author and source are credited.

\section{ABSTRACT}

A substantial segment of patients with acute myeloid leukemia (AML) will relapse following an initial response to induction therapy or will prove to be primary refractory. High-dose cytarabine and mitoxantrone (HiDAC/MITO) is an established salvage therapy for these patients. We studied all adult patients with relapsed/ refractory $(R / R)$ AML who were treated with HiDAC/MITO in our center between the years 2008-2017. To determine whether responding patients harbored a unique molecular signature, we performed targeted next-generation sequencing (NGS) on a subset of patients. The study cohort consisted of 172 patients with a median age of 54 years (range 18-77). The composite complete remission rate was $58 \%$; 11 patients $(6 \%)$ died during salvage therapy. Median survival was 11.4 months with a 1 -year survival rate of $\mathbf{4 8} \%$. In multivariate analysis favorable risk cytogenetics [Odds ratio $(O R)=0.34$, confidence interval $(C I) 95 \%, 0.17-0.68 ; P=0.002$ ], and denovo AML (OR = 0.4, CI 95\%, 0.16-0.98; $P=0.047$ ) were independently associated with a favorable response. Patients who attained a complete remission had a median survival of $\mathbf{4 3 . 7}$ months compared with $\mathbf{5 . 2}$ months for refractory patients $(p<$ 0.0001). Neither the FLT3-ITD and NPM1 mutational status nor the indication for salvage therapy significantly impacted on the response to HiDAC/MITO salvage. NGS analysis identified 20 different mutations across the myeloid gene spectrum with a distinct TP53 signature detected in non-responding patients. HiDAC/MITO is an effective salvage regimen in $R / R A M L$, however patients with adverse cytogenetics or secondary disease may not benefit as much from this approach.

\section{INTRODUCTION}

While most patients with acute myeloid leukemia (AML) will achieve an initial remission following induction chemotherapy [1], up to $40 \%$ of patients will experience induction failure [2-5], and nearly half of the younger patient population (60 years or younger) achieving a first complete remission (CR1) will eventually relapse with older patients experiencing relapse rates reaching upwards to $80 \%[6,7]$. Prognosis for this clinically challenging patient segment is quite poor with long term survival being realized in only a small fraction of patients treated both with intensive and nonintensive approaches [8-10]. Notwithstanding the recent introduction of novel agents targeting clinically actionable mutations such as FLT3-ITD [11], IDH1 [12], and IDH2 [13], many patients with relapsed/refractory (R/R) disease are still currently treated with cytotoxic chemotherapy based salvage regimens. However, at present there is no clearly established standard of care with regard to a specific salvage regimen in patients with $\mathrm{R} / \mathrm{R}$ AML, indicated by a substantial body of literature published over the last three decades [14-24]. Indeed, in the absence of head-to-head comparisons of the multitude of regimens 
currently used [25], ascertaining the superiority of a given therapeutic approach and predicting which patient subsets are most likely to benefit from a specific salvage regimen is a central challenge. One of the established salvage protocols for R/R AML patients is high dose cytarabine (HiDAC) and mitoxantrone (MITO) as the initial salvage regimen based on favorable experience with this regimen [26-28]. In this study we endeavored to reassess the clinical efficacy of HiDAC/MITO in $172 \mathrm{R} / \mathrm{R}$ AML patients treated in our center and determine clinical and lab parameters of potential predictive value of therapeutic efficacy. Moreover, as next generation sequencing (NGS) is gaining increased acceptance as an innovative modality in AML for genomic classification [29], risk stratification [30], and tracking of minimal residual disease [31], we sought to investigate whether NGS profiling can predict for treatment response in our patients treated with HiDAC/ MITO.

\section{RESULTS}

\section{Patients and baseline characteristics}

Between January 2008 and April 2017, a hundred and seventy-two patients were treated with HiDAC/MITO salvage for R/R AML. The median age was 54 years with a range of 18-77 years. Patient disposition with regard to treatment allocation during the study period is delineated in Supplementary Figure 1. As outlined in Table 1, a hundred and forty-four (84\%) patients had de-novo AML, 24 (14\%) had a prior diagnosis of the myelodysplastic syndrome (MDS), and $4(2 \%)$ had an antecedent myeloproliferative neoplasm (MPN). Seventeen (10\%) patients had favorable risk cytogenetics, $121(72 \%)$ had intermediate risk cytogenetics, and 30 (18\%) had high-risk cytogenetics. Fifty-one patients harbored the FLT3-ITD mutation whereas 41 (29\%) were NPM1 mutated. All patients received standard single induction with an anthracycline for 3 days concurrent with continuous infusion of cytarabine at $100 \mathrm{mg} / \mathrm{m}^{2}$ for 7 days. Ninety-three (54\%) patients were treated with HiDAC/MITO salvage for primary refractory disease, 44 (26\%) for disease relapse, and 35 (20\%) for relapse following allo-SCT. Concurrent DLI was given to 13 patients. Patients received DLI at a median of 3 days after HiDAC/MITO with a median dose of administered cells of $9.6 \times 10^{7} \mathrm{CD} 3 / \mathrm{kg}$ (range $0.5-19.6 \times 10^{7} \mathrm{CD} 3 \mathrm{~kg}$ ). $8 / 13$ patients achieved CR/CRi (62\%), no statistically significant difference in terms of response was observed between patients given DLI and those not receiving DLI ( $p=\mathrm{NS}$ ). The median survival was 5.8 months for patients administered DLI (range 2.2-78 months), and survival was not significantly different between groups $(p=0.38)$.

Transplant related data are summarized in Supplementary Table 1, most of the transplanted patients (78\%) in the analyzed cohort underwent a 10/10 HLA matched transplant either from a matched sibling or a matched unrelated donor, and 7 patients who relapsed post-transplant underwent a second transplant following salvage treatment with HiDAC/MITO.

\section{Response to salvage therapy}

A hundred patients (58\%) achieved a composite complete remission and $61(36 \%)$ were refractory to treatment (Table 2). Eleven (6\%) patients died during treatment. For patients achieving a composite complete remission and who did not have a prior allo-SCT the median duration of remission following HiDAC/MITO was 83 days (range 61-251 days). For those patients who relapsed following a prior allo-SCT the median duration of remission duration following $\mathrm{HiDAC} /$ MITO was 310 days (range 52-1193 days). A univariate analysis (Supplementary Table 2) was performed to assess the effect of clinical parameters on the likelihood of achieving a complete remission (CR). There was no significant association of gender, WBC count at initial diagnosis, presence of extramedullary disease, type of initial induction chemotherapy, and use of DLI with attainment of a complete remission. The indication for salvage chemotherapy ( $i$. e. refractory versus relapsed disease), and the presence of either a FLT-ITD or an NPM1 mutation were also not significantly different between patients who achieved a complete remission versus those who did not. Younger patients were more likely to achieve a CRc, the mean age for patients achieving a CRc was 48 years compared to 54 years for non-responding patients $(p=0.019)$. The cytogenetic risk category was significantly associated with rate of CRc, patients with favorable risk cytogenetics had a 100\% rate of CRc, patients with intermediate risk cytogenetics were more likely to be in the CRc group (56\%) while those with adverse-risk cytogenetics were more likely to be in the non-responding group (53\%) $(p=0.001)$. Type of AML was also significantly different between responders and non-responders whereby patients with de novo AML were more likely to respond (63\% vs. $37 \%$ ) while patients with antecedent MDS or MPN were less likely to be in the responding group (37\% vs. $63 \%$ and $25 \%$ vs. $75 \%$, respectively; $p=0.028$ ). Table 3 summarizes the multivariate analysis demonstrating that cytogenetic risk category to be significantly associated with likelihood of remission (odds ratio $(\mathrm{OR})=0.34,95 \%$ confidence interval (CI) $0.17-0.68, P=0.002$ ). Type of AML was also significantly associated with likelihood of remission $(\mathrm{OR}=$ $0.4,95 \%$ CI $0.16-0.98, P=0.047)$. There was a statistical trend toward a younger age being associated with response to therapy $(\mathrm{OR}=0.98,95 \% \mathrm{CI} 0.95-1.003, P=0.097)$.

\section{Survival analysis}

Overall, the median survival for the cohort analyzed as a whole was 11.4 months (95\% CI 7.5 
Table 1: Baseline characteristics of study population

\section{Clinical Parameter}

Year of diagnosis, median (range)

Follow up duration in $\mathrm{m}$, median (range)

Age in $\mathrm{y}$, median (range)

Gender, n(\%)

Male

Female

WBC at diagnosis $\left(\times 10^{9} / \mathrm{L}\right)$, median (range)

WBC at time of HiDAC/MITO initiation $\left(\times 10^{9} / \mathrm{L}\right.$, median (range)

Platelet at time of HiDAC/MITO initiation, median (range)

Creatinine at time of HiDAC/MITO initiation, median (range)

Initial remission duration in $\mathrm{m}$, median (range)

MRC cytogenetic risk category, $\mathrm{n}(\%)$

Favorable

Intermediate

Adverse

Missing

AML type, n(\%)

De-novo

MDS

MPN

Extramedullary disease, $\mathrm{n}(\%)$

No

Yes

FLT3-ITD status, n(\%)

Wild type

Mutated

Missing

NPM1 status, $\mathrm{n}(\%)$

Wild type

Mutated

Missing

Mutational status, $\mathrm{n}(\%)$

FLT3 $^{\mathrm{wt}} / N P M 1^{\mathrm{wt}}$

$F{ }^{\mathrm{wt}} / N P M 1^{\mathrm{mut}}$

FLT3 $^{\mathrm{mut}} / N P M 1^{\mathrm{wt}}$

$F L T 3^{\text {mut }} / N P M 1^{\text {mut }}$

Induction Chemotherapy, $\mathrm{n}(\%)$

Daunorubicin $45 \mathrm{mg} / \mathrm{m}^{2}$

Daunorubicin $60 \mathrm{mg} / \mathrm{m}^{2}$

Daunorubicin $90 \mathrm{mg} / \mathrm{m}^{2}$

Idarubicin $12 \mathrm{mg} / \mathrm{m}^{2}$

Other

Missing
Entire cohort $(\mathbf{N}=172)$

$$
\begin{gathered}
2013(2006-2016) \\
16(0.9-116) \\
54(18-77) \\
87(51) \\
85(49) \\
14(0.2-233) \\
3.7(0.5-118.1) \\
89(4-581) \\
0.82(0.27-3.39) \\
8(0.5-72)
\end{gathered}
$$

17 (10)

$121(72)$

30 (18)

4

$144(84)$

24 (14)

4 (2)

$156(91)$

$16(9)$

107 (68)

51 (32)

14

$102(71)$

41 (29)

29

77 (54)

23 (16)

25 (17)

18 (13)

$107(71)$

$5(3)$

9 (6)

2 (1)

22 
Disease status, $\mathrm{n}(\%)$

Primary refractory $\quad 93$ (54)

Relapse $\quad 44$ (26)

Relapse following stem cell transplantation $\quad 35$ (20)

DLI combined with salvage chemotherapy, $\mathrm{n}(\%)$

Yes

WBC: white blood cells; MRC: Medical Research Council; NPM1: nucleophosmin1; FLT3-ITD: FMS-like tyrosine kinase-3 internal tandem duplication; DLI: donor lymphocyte infusion.

Table 2: Clinical outcomes for patient treated with salvage HiDAC/MITO

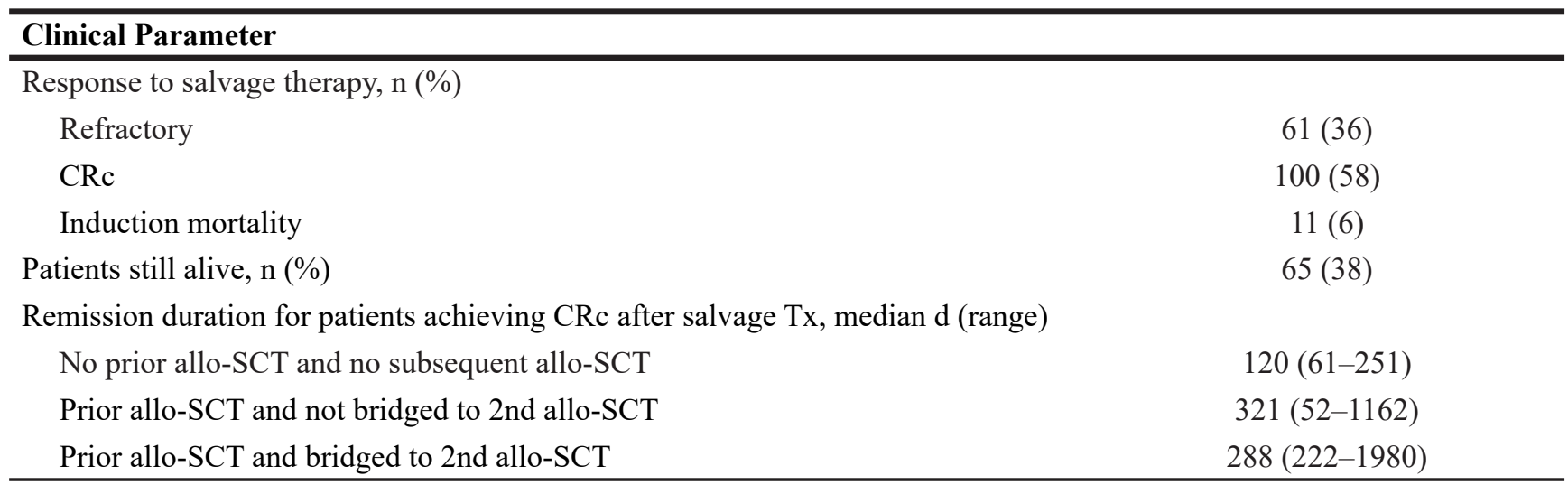

CRc: composite complete remission; allo-SCT: allogeneic stem cell transplantation.

Table 3: Multivariate analysis of factors impacting on response to HiDAC/MITO

\begin{tabular}{lccc}
\hline & OR & 95\% CI & P \\
\hline Age at diagnosis & 0.98 & $0.95-1.003$ & 0.097 \\
MRC cytogenetic risk category & & & $0.17-0.68$ \\
De novo AML & 0.34 & & 0.002 \\
\hline
\end{tabular}

MRC: Medical Research Council; OR: odds ratio; CI: confidence interval.

15.2 months) with a 1-year survival rate of $48 \%$ (Supplementary Figure 2). As shown in Figure 1, the median overall survival for patients who attained a CRc with HiDAC/MITO was 43.7 months (95\% CI 14.3-73.2 months) compared with 5.2 months (95\% CI 3.5-6.9 months) for patients who were refractory to treatment $(p<0.0001)$. The indication for salvage treatment had significant impact on overall survival whereby patients treated with salvage chemotherapy for disease relapse post allo-SCT experienced worse survival compared to patients treated for either relapsed or refractory disease (median survival of 5.8 months versus 25.8 and 14.6 months, respectively; $p=0.001$ ). Figure 2 outlines the outcome of patients according to the cytogenetic risk category revealing distinctly worse outcomes for patients with adverse risk cytogenetics compared to their counterparts with intermediate and favorable risk cytogenetic studies $(p=0.002)$. The presence of a FLT3ITD mutation was not significantly associated with overall survival (Supplementary Figure 3). Next, we wanted to assess the duration of remission for patients who responded to HiDAC/MITO. Notably, in patients without a previous allo-SCT, who responded to HiDAC/ MITO and did not undergo a subsequent allo-SCT, the median duration of remission was 120 days (range 61-251 days). Conversely, when analyzing the patient subset of post-transplant relapses and who responded to $\mathrm{HiDAC} / \mathrm{MITO}$, we observed that patients bridged to a second transplant experienced a significantly longer remission duration (median duration of 288 days; range 222-1980 days, $p=0.027$ ) whereas responding patients who were not bridged to a second transplant had a 
median remission duration of 321 days (range 52-1162 days) with no significant difference between both groups $(p=0.18)$.

\section{Next generation sequencing}

To assess whether the response to HiDAC/MITO could be predicted based on a specific myeloid molecular signature we performed next generation sequencing on a subset of 25 patient samples which were available for sequencing. As shown in Table 4, the NGS studies identified a multitude of mutations in myeloid associated genes. In aggregate, 20 different mutations were detected in both the responding and non-responding groups. Overall, in the responding group, DNMT3A (4), TP53 (2), KIT (2), RUNX1 (2), IDH2 (2), KRAS (2), and KDMT6A (2) were the most common identified mutations. In the non-responding group mutations in TP53 (4), DNMT3A (3), and $B C O R$ (2) were the most common mutations detected. In three patient samples none of the 54 mutations detectable with the NGS platform used in this study were identified. Non-responding patients were significantly more likely to harbor TP53 mutations compared to patients who responded to salvage chemotherapy $(p=0.026)$. Of note, five of the six patients with TP53 mutations harbored adverse risk cytogenetics.

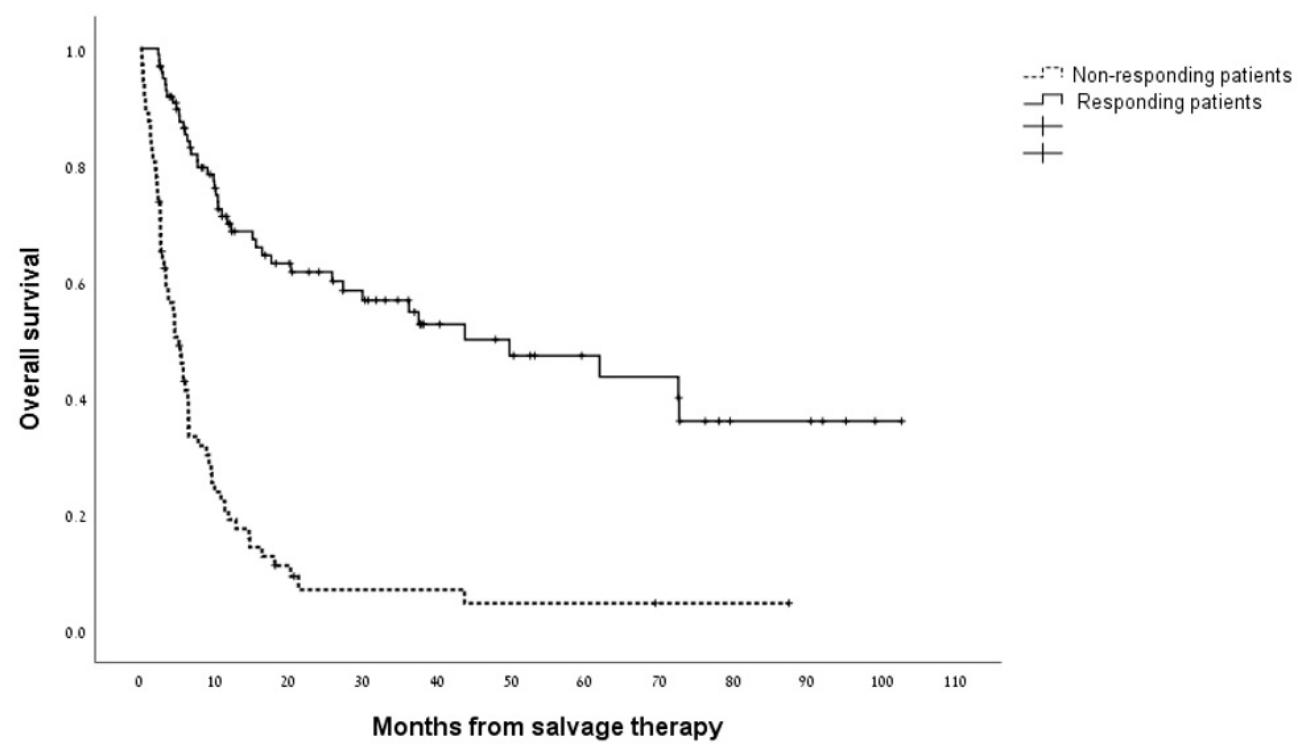

Figure 1: Kaplan-Meier estimate of overall survival in responding patients and non-responding patients to treatment with HiDAC/MITO.

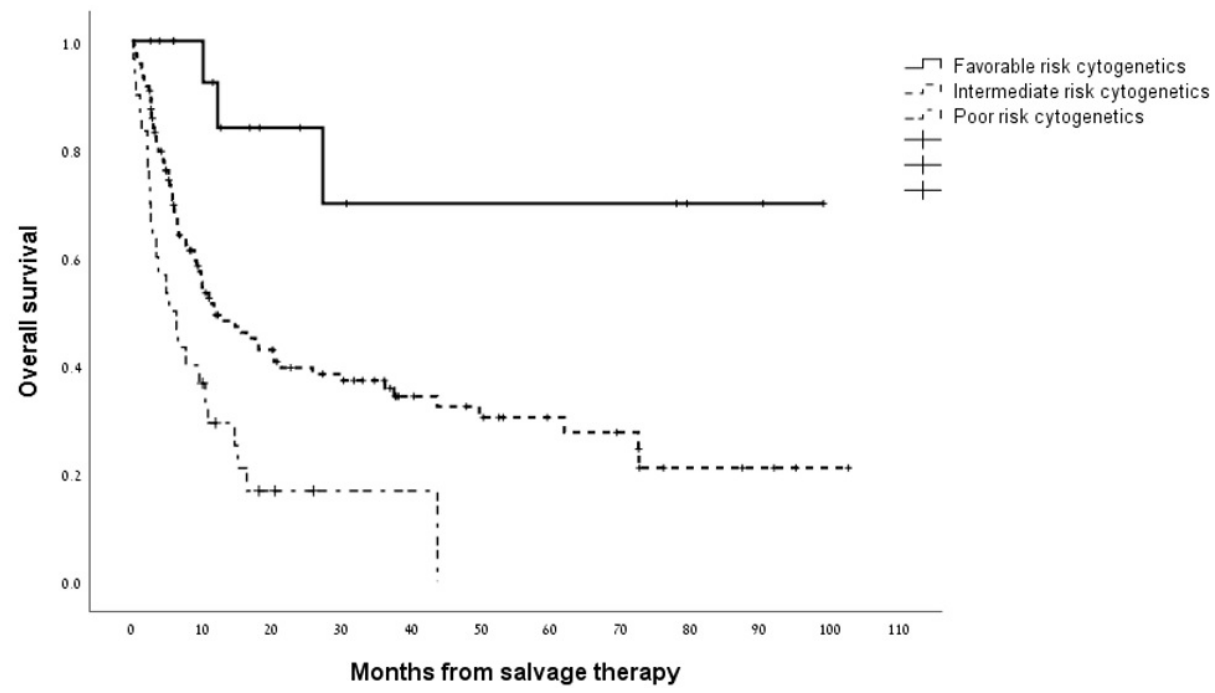

Figure 2: Kaplan-Meier estimate of overall survival according to cytogenetic risk group. 


\section{DISCUSSION}

Whereas targeting of molecular aberrations and epigenetic dysregulation is an area of flux in AML, standard cytotoxic chemotherapy remains the benchmark for evaluating the efficacy and safety of new therapies in AML. This speaks to the need to reevaluate established cytotoxic based therapies with recent clinical data complemented with the use of novel molecular tools. In this analysis of 172 patients with R/R AML we show that using the HiDAC/MITO regimen in this clinical setting is associated with a high remission rate concomitant to a low treatment related mortality rate. Further, using NGS in a subgroup of patients, our data reveal that our patient population, irrespective of response pattern, is enriched for a broad spectrum of mutations in myeloid malignancy associated genes with a unique TP53 signature detected in the non-responding patient subset.

$\mathrm{R} / \mathrm{R}$ AML continues to constitute a formidable challenge in the hemato-oncological arena resulting in generally poor long-term outcomes. The intense clinical efforts in the field are evident by the copious number of clinical studies using both standard and investigational agents. Indeed, only in the past decade several major international collaborations have investigated the roles of vosaroxin [32], elacytarabine [33], laromustine [21], and azacitidine [34] in R/R AML. Despite these and other efforts, response rates and perhaps more importantly survival rates have for the most part shown suboptimal results with commonly used regimens such as MEC [15], FLAG-IDA [35], HiDAC [14], azacitidine [34], and clofarabine [22] combinations achieving responses in the range of $16 \%-54 \%$ and long term survival of less than 12 months for most patients.

These data reaffirm historical publications showing HiDAC/MITO to be a robust and effective salvage regimen for patients with $\mathrm{R} / \mathrm{R}$ AML, furthermore our current data in the era of modern supportive care and highly effective antimicrobial agents, show superior results to those published earlier. Indeed, these outcomes compare favorably with the Southwest Oncology Group phase III trial showing a $6 \%$ therapy related mortality compared with $17 \%$, and a $58 \%$ rate compared with $44 \%$ [27]. We note that our results concur with historical data published by our center two decades ago showing also CR rates of over 50\% [28]. Decidedly, the improvement in outcomes for AML patients as a whole and for R/R patients can be accounted for by the marked improvement in treatment of infections [36, 37] and supportive care [38, 39], also supported by a recent analysis of the European Society for Blood and Marrow Transplantation showing markedly better outcomes for more recently transplanted patients compared to historical results [40]. Analogue studies with R/R AML salvage regimens have identified age at initial diagnosis, duration of CR1, cytogenetic risk group, and no prior
allo-SCT as predictors of outcome in this clinical setting $[10,41,42]$. This analysis confirms the validity of these clinical variables also in our patient population with superior remission rates seen in younger patients, those with favorable risk cytogenetics, and in patients with no antecedent myeloid disorder. Notably, we did not find that the presence of FLT3-ITD to be predictive of the likelihood of either response or overall survival which diverges from the experience of the PETHEMA group with FLAG-IDA and of the GOELAMS study group which studied outcomes of R/R AML patients with various salvage regimens with combined gemtuzumab ozogamicin [42, 43]. In contrast, a recent analysis from the German-Austrian AML Study Group in over 3,300 $\mathrm{R} / \mathrm{R}$ patients treated on several prospective salvage regimens also did not identify the presence of a FLT3ITD mutation as predictive of response to salvage therapy although patients harboring this mutation did experience worse overall survival [2]. It is likely the discrepant results regarding the prognostic role of FLT3-ITD in R/R AML result from the retrospective nature of these studies as well as the heterogenous composition of patients and salvage regimens studied. Unlike previous publications showing a beneficial impact on response to salvage chemotherapy [44], our results argue that in the setting of R/R AML, mutated NPM1 status does not contribute to improved outcomes, a supposition supported also by a recent analysis by Schlenk and colleagues [5].

Precision medicine is proving to be a transformative approach in hematology and given the incremental advances realized in the field's understanding of the genomic landscape in de novo AML $[29,45]$ as well as $R / R$ AML [46], it is of significant importance to molecularly interrogate the clinically challenging population of $\mathrm{R} / \mathrm{R}$ AML patients. The NGS analysis in 25 patients treated with HiDAC/MITO reveals a wide range of mutations along the myeloid gene spectrum comprising mutations in genes related to chromatin modification, tumor suppression, activated signaling, myeloid transcription factors, and DNA methylation. While our study was not powered sufficiently to detect a statistically significant molecular signature unique to either HiDAC/MITO responsive or non-responsive patients, we did find that the non-responding patient subset was enriched for TP53 mutations which is in line with previous publications corroborating the detrimental impact of TP53 in AML patients [47]. Our findings extend on recent studies exploring the pivotal role of NGS studies in investigating resistance mechanisms to novel targeted agents used in AML such as gilteritinib [48], crenolanib [49], and ivosidenib [50]. Notably, these studies and our findings lend further credence to the importance of upfront molecular profiling of patients in order to predict outcome and allow for timely allocation of patients with low chances of responding to a given therapy to clinical trials, perhaps best exemplified by the Beat AML Master 
Table 4: Mutations detected in relapsed/refractory AML patients grouped by response to HiDAC/MITO

\begin{tabular}{|c|c|c|c|}
\hline Patient & Clinical response & Mutation (VAF\% AA) & Genomic Subgroup \\
\hline PT1107 & Responded to salvage Tx & BCORL1 (100\% N1382K) & $\begin{array}{l}\text { AML with mutated chromatin or } \\
\text { RNA-splicing genes }\end{array}$ \\
\hline PT1108 & Responsed to salvage $\mathrm{Tx}$ & $\begin{array}{c}\text { KRAS }(11 \% \text { G12C) } \\
\text { NOTCH1 (53\% L2457V) }\end{array}$ & AML with inv(16)(p13.1q22) \\
\hline PT1125 & Responded to salvage Tx & $\begin{array}{c}\text { DNMT3A (48\% R729W) } \\
\text { IDH1 (52\% R132C) } \\
\text { TP53 (9\% P309S) }\end{array}$ & $\begin{array}{l}\text { AML with TP53 mutations and/or } \\
\text { chromosomal aneuploidy }\end{array}$ \\
\hline PT1130 & Responded to salvage Tx & $\begin{array}{l}\text { KDM6A }(13 \% \text { E1102K) } \\
\text { RUNX1 (8\% A123T) }\end{array}$ & AML with $\mathrm{t}(8 ; 21)(\mathrm{q} 22 ; \mathrm{q} 22)$ \\
\hline PT1132 & Responded to salvage Tx & $\begin{array}{c}\text { DNMT3A (45\% R484fs) } \\
\text { NPM1 (45 \%W288fs) }\end{array}$ & AML with NPM1 mutation \\
\hline PT1133 & Responsed to salvage $\mathrm{Tx}$ & $\begin{array}{l}\text { DNMT3A }(37 \% \text { R882H) } \\
\text { IDH2 (36\% R172) } \\
\text { ATRX (13\% D1681G) }\end{array}$ & AML with $M L L$ fusion genes \\
\hline PT1138 & Responded to salvage Tx & $\begin{array}{c}\text { NRAS }(96 \% \text { Q61R }) \\
\text { TP53 }(8.5 \% \text { A347D) } \\
\text { STAG2 }(23 \% \text { F178l }) \\
\text { CBL }(46 \% \text { c. } 1227+4 c>\text { T })\end{array}$ & $\begin{array}{l}\text { AML with TP53 mutations and/or } \\
\text { chromosomal aneuploidy }\end{array}$ \\
\hline PT1141 & Responsed to salvage Tx & $\begin{array}{c}\text { FLT3 (21\% V592D) } \\
\text { KIT (9\% N822K) }\end{array}$ & AML with $\mathrm{t}(8 ; 21)(\mathrm{q} 22 ; \mathrm{q} 22)$ \\
\hline PT1142 & Responded to salvage Tx & KIT (49\% Y578C) & AML with inv(16)(p13.1q22) \\
\hline PT1143 & Responsed to salvage Tx & $\begin{array}{c}\text { IDH2(47\% R172K) } \\
\text { KRAS }(39 \% \text { G12D) } \\
\text { TET2 }(55 \% \text { P1723S, } \\
48 \% \text { Y } 867 \mathrm{H})\end{array}$ & AML with IDH2 $2^{\mathrm{R} 172}$ mutations \\
\hline PT1126 & Responded to salvage Tx & $\begin{array}{c}\text { RUNX1 (53\% R162K) } \\
\text { DNMT3A (39\% c.2174-2A>G) } \\
\text { SRSF2 (31\% R94dupGCC) }\end{array}$ & $\begin{array}{l}\text { AML with mutated chromatin or } \\
\text { RNA-splicing genes }\end{array}$ \\
\hline PT1149 & Responsed to salvage Tx & KDM6A (49\% L915S) & $\begin{array}{l}\text { AML with no detected driver } \\
\text { mutations }\end{array}$ \\
\hline PT1153 & Responded to salvage Tx & $\begin{array}{c}\text { BCOR }(24 \% \text { P624S }) \\
\text { WT }(13 \% \text { P390T })\end{array}$ & AML with inv(16)(p13.1q22) \\
\hline P1109 & Refractory to salvage Tx & $\begin{array}{c}\text { IDH2 }(40 \% \text { R } 172 \mathrm{~K}) \\
\text { DNMT3A }(32 \% \text { F372indel }) \\
\text { KRAS }(100 \% \text { A } 11 \mathrm{~T})\end{array}$ & $\begin{array}{l}\text { AML with TP53 mutations and/or } \\
\text { chromosomal aneuploidy }\end{array}$ \\
\hline PT1137 & Refractory to salvage $\mathrm{Tx}$ & DNMT3A (36\% L737F) & $\begin{array}{l}\text { AML with driver mutations but no } \\
\text { detected class-defining lesions }\end{array}$ \\
\hline PT1139 & Refractory to salvage Tx & DNMT3A (44\% R882H) & $\begin{array}{l}\text { AML with driver mutations but no } \\
\text { detected class-defining lesions }\end{array}$ \\
\hline PT1144 & Refractory to salvage $\mathrm{Tx}$ & $\begin{array}{l}\text { NPM1 }(15 \% \text { C.759-1G>C) } \\
\text { CSF3R }(51 \% \text { E } 808 K)\end{array}$ & AML with NPM1 mutation \\
\hline PT1145 & Refractory to salvage Tx & $\begin{array}{c}\operatorname{ATRX}(25 \% \text { Y } 203 *, 16 \% \text { D } 207 V) \\
\text { CBL }(49 \% \text { c. } 1227+4 C>T)\end{array}$ & $\begin{array}{l}\text { AML with TP53 mutations and/or } \\
\text { chromosomal aneuploidy }\end{array}$ \\
\hline
\end{tabular}




\begin{tabular}{|c|c|c|c|}
\hline PT1147 & Refractory to salvage Tx & $\begin{array}{c}\text { TP53 (86\% Splice Site) } \\
\text { BCOR (30\% R1532S, 15\% H1542D) } \\
\text { EZH2 (13\% Q420*) } \\
\text { KIT }(12 \% \mathrm{I} 542 \mathrm{~F})\end{array}$ & $\begin{array}{l}\text { AML with TP53 mutations and/or } \\
\text { chromosomal aneuploidy }\end{array}$ \\
\hline PT1151 & Refractory to salvage Tx & $\begin{array}{l}\text { TP53 }(47 \% \text { R110H) } \\
\text { FLT3 }(45 \% \text { D835E) } \\
\text { RUNX1 (44\% R201*) } \\
\text { ETV6 (36\% R369W) } \\
\text { IKZF1 (40\% K58fs*5) } \\
\text { TET2 }(33 \% \text { R1452*) }\end{array}$ & $\begin{array}{l}\text { AML with TP53 mutations and/or } \\
\text { chromosomal aneuploidy }\end{array}$ \\
\hline PT1152 & Refractory to salvage $\mathrm{Tx}$ & $\begin{array}{c}\text { TP53 (18\% K114R) } \\
\text { KIT (52\% V50L) } \\
\text { BCOR }(8 \% \text { D1352N) }\end{array}$ & $\begin{array}{l}\text { AML with TP53 mutations and/or } \\
\text { chromosomal aneuploidy }\end{array}$ \\
\hline PT1128 & Refractory to salvage Tx & TP53 (59\% T125M) & $\begin{array}{l}\text { AML with TP53 mutations and/or } \\
\text { chromosomal aneuploidy }\end{array}$ \\
\hline
\end{tabular}

VAF: variant allele frequency; AA: amino acid.

Trial [51] randomizing patients to study arms based on baseline mutational data.

Considering the known adverse effect of TP53 mutations in AML in general, and specifically as our data indicate in $\mathrm{R} / \mathrm{R}$ AML treated with HiDAC/ MITO salvage therapy, it is hoped and anticipated that specific targeting of wild-type and mutated TP53 via MDM2, the main negative regulator of TP53, may improve patient outcomes. Indeed, ongoing clinical studies with MDM2 antagonists such as idasanutlin (NCT02545283), milademetan (NCT03634228), and KRT-232 (NCT03041688) are being actively conducted in R/R AML patients. Furthermore, our data lay further credence to the use of HiDAC/MITO as a chemotherapy backbone in innovative clinical trials incorporating novel agents such as the phase III trial assessing in older patients with R/R AML the combination of HiDAC/MITO and CPI-613, a mitochondrial tricarboxylic acid cycle inhibitor (NCT03504410) which has shown promising activity in a phase 1 study [52] or in combination with the FLT3 inhibitors quizartinib and crenolanib (NCT03250338 and NCT03250338, respectively).

As this was a retrospective analysis, we acknowledge that inherent biases in data collection may potentially affect interpretation of results and thus merit prudent interpretation. Additionally, it is noted that while in this study refractory disease was defined as failure to achieve remission after one cycle of intensive chemotherapy, there is a plurality of working definitions for refractory disease $[4,6,53]$.

In summary, HiDAC/MITO is a highly effective salvage regimen for patients with relapsed/refractory AML and retains an important place in the current armamentarium of therapies for this patient population. Our study emphasizes the significant value of employing
NGS modalities for prediction of response to therapy in AML patients.

\section{MATERIALS AND METHODS}

\section{Study population}

This was a retrospective analysis of 172 consecutive patients with $\mathrm{R} / \mathrm{R}$ AML who were treated with the HiDAC/MITO salvage regimen between January 2008 and April 2017. Adult patients aged $\geq 18$ years were eligible for analysis if they had relapsed or refractory disease according to standard international Working Group Criteria [54]. Refractory disease was defined as failure to achieve remission after 1 course of intensive induction chemotherapy. Assessment of cytogenetic risk category was performed according to the modified United Kingdom Medical Research Council criteria [55]. Assignment of patients to specific genomic subgroups was undertaken as previously published [29]. This retrospective analysis was approved by the Institutional Review Board of the Chaim Sheba Medical Center.

\section{Treatment plan}

Patients received intravenous mitoxantrone at $20 \mathrm{mg} / \mathrm{m}^{2}$ on days $1-2$ over 30 minutes with dose reduction to $15 \mathrm{mg} / \mathrm{m}^{2}$ for patients over 60 years of age or those deemed to have clinically significant co-morbidities. Immediately following completion of administration of mitoxantrone, patients received cytarabine at $3 \mathrm{~g} / \mathrm{m}^{2}$ intravenously over three hours on days 1-5 with dose reduction to $1 \mathrm{~g} / \mathrm{m}^{2}$ for patients over 60 years of age. Supportive care included antifungal prophylaxis following completion of therapy for the duration of neutropenia. 


\section{Statistical analysis}

The primary endpoints of interest in this analysis were the composite complete remission rate $(\mathrm{CRc})$ and survival. Complete remission (CR) was defined as a neutrophil count of $\geq 1000 / \mu \mathrm{L}$ and a platelet count of $\geq$ $100,000 / \mu \mathrm{L}$, and less than $5 \%$ blasts in the bone marrow, and complete remission with incomplete hematologic recovery (CRi) was defined as all $\mathrm{CR}$ criteria except for residual neutropenia $\left(<1.0 \times 10^{9} / \mathrm{L}[1000 / \mu \mathrm{L}]\right)$ or thrombocytopenia $\left(<100 \times 10^{9} / \mathrm{L}[100,000 / \mu \mathrm{L}]\right)$ [6]. Induction mortality was defined as any death occurring within 30 days of administration of salvage chemotherapy. Overall survival was calculated from the initial day of salvage therapy to death from any cause or to time of last follow up. Univariate analyses were performed using $T$-Test for continuous variables, and Fisher's Exact test and Pearson's chi-squared for assessment of categorical variables. Probability of overall survival was determined using the Kaplan-Meier estimate, and comparison of survival between groups was assessed with the log-rank test. Multivariate analyses using logistic regression were performed using age, patient gender, WBC at diagnosis, initial remission duration, cytogenetic risk category, type of AML (de novo/secondary), presence of extramedullary disease, FLT3-ITD and NPM1 status, type of induction chemotherapy, time from diagnosis to allo-SCT, indication for salvage chemotherapy (refractory, relapsed, post-stem cell transplantation relapse), and use of donor lymphocyte infusion (DLI) with salvage chemotherapy as covariates. All tests were two-sided with the type I error rate fixed at 0.05 for the determination of factors associated with timeto-event outcomes. Statistical analyses were performed using the SPSS 25.0 (SPSS Inc, Chicago, IL, USA).

\section{Targeted next-generation sequencing}

Using bone marrow samples obtained at the time of diagnosis we performed targeted next-generation sequencing (NGS) of 54 myeloid cancer associated genes with the Illumina TruSight Myeloid Sequencing Panel, following the manufacturer's protocol. Briefly, high quality DNA was extracted using the QIAcube (Qiagen, Venlo, The Netherlands). DNA concentration was measured by Qubit Fluorometric Quantitation (Thermo Fisher Scientific, Wilmington, DE). The NGS libraries were sequenced on an Illumina MiSeq System (Illumina, San Diego, CA). Reads were aligned to the human reference genome version 19 (hg19) to create BAM files. The somatic variant caller was then performed for variant analysis of the specific regions in the manifest. Single nucleotide variants (SNVs) and insertions-deletions (indels) at diagnosis were analyzed using the Illumina MiSeq Reporter software and subsequently with Ingenuity software (Qiagen). Variant allele frequencies (VAF) of mutations were calculated as the ratio between the number of mutant and total reads.

\section{Abbreviations}

AML: acute myeloid leukemia; CR: complete remission; HiDAC/MITO: high-dose cytarabine and mitoxantrone; NGS: next-generation sequencing; OS: overall survival; $\mathrm{CI}$ : confidence interval; R/R: relapsed/refractory; allo-SCT: allogeneic stem cell transplantation.

\section{Author contributions}

$\mathrm{JC}, \mathrm{MN}$, and AN designed the research and/or analyzed the data. JC and AN wrote the manuscript. GH, CG, RY, NST, YV, DM, AA, AS, NA and GR, provided clinical data and commented on manuscript. All authors read and approved the final manuscript.

\section{ACKNOWLEDGMENTS AND FUNDING}

This work was supported by a grant from the Varda and Boaz Dotan research center in Hemato-Oncology at the Tel Aviv University's Cancer Biology Research Center.

\section{CONFLICTS OF INTEREST}

None.

\section{REFERENCES}

1. Walter RB, Othus M, Burnett AK, Löwenberg B, Kantarjian HM, Ossenkoppele GJ, Hills RK, Ravandi F, Pabst T, Evans A, Pierce SR, Vekemans MC, Appelbaum FR, Estey EH. Resistance prediction in AML: analysis of 4601 patients from MRC/NCRI, HOVON/SAKK, SWOG and MD anderson cancer center. Leukemia. 2015; 29:312-20. https://doi.org/10.1038/leu.2014.242. [PubMed]

2. Wattad M, Weber D, Döhner K, Krauter J, Gaidzik VI, Paschka P, Heuser M, Thol F, Kindler T, Lübbert M, Salih HR, Kündgen A, Horst HA, et al. Impact of salvage regimens on response and overall survival in acute myeloid leukemia with induction failure. Leukemia. 2017; 31:1306-13. https:// doi.org/10.1038/leu.2017.23. [PubMed]

3. Ravandi F, Cortes J, Faderl S, O'Brien S, Garcia-Manero G, Verstovsek S, Santos FP, Shan J, Brandt M, de Lima M, Pierce S, Kantarjian H. Characteristics and outcome of patients with acute myeloid leukemia refractory to 1 cycle of high-dose cytarabine-based induction chemotherapy. Blood. 2010; 116:5818-23. https://doi.org/10.1182/blood2010-07-296392. [PubMed]

4. Ferguson P, Hills RK, Grech A, Betteridge S, Kjeldsen L, Dennis M, Vyas P, Goldstone AH, Milligan D, Clark RE, Russell NH, Craddock C, and UK NCRI AML Working Group. An operational definition of primary refractory acute myeloid leukemia allowing early identification of patients who may benefit from allogeneic stem cell 
transplantation. Haematologica. 2016; 101:1351-58. https:// doi.org/10.3324/haematol.2016.148825. [PubMed]

5. Schlenk RF, Frech P, Weber D, Brossart P, Horst HA, Kraemer D, Held G, Ringhoffer M, Burchardt A, Kobbe G, Götze K, Nachbaur D, Fischer T, et al, and the GermanAustrian AMLSG. Impact of pretreatment characteristics and salvage strategy on outcome in patients with relapsed acute myeloid leukemia. Leukemia. 2017; 31:1217-20. https://doi.org/10.1038/leu.2017.22. [PubMed]

6. Döhner H, Estey E, Grimwade D, Amadori S, Appelbaum FR, Büchner T, Dombret H, Ebert BL, Fenaux P, Larson RA, Levine RL, Lo-Coco F, Naoe T, et al. Diagnosis and management of AML in adults: 2017 ELN recommendations from an international expert panel. Blood. 2017; 129:424-47. https://doi.org/10.1182/blood-2016-08733196. [PubMed]

7. Dombret H, Gardin C. An update of current treatments for adult acute myeloid leukemia. Blood. 2016; 127:53-61. https://doi.org/10.1182/blood-2015-08-604520. [PubMed]

8. Thol F, Schlenk RF, Heuser M, Ganser A. How I treat refractory and early relapsed acute myeloid leukemia. Blood. 2015; 126:319-27. https://doi.org/10.1182/blood2014-10-551911. [PubMed]

9. Ganzel C, Sun Z, Cripe LD, Fernandez HF, Douer D, Rowe JM, Paietta EM, Ketterling R, O'Connell MJ, Wiernik PH, Bennett JM, Litzow MR, Luger SM, et al. Very poor longterm survival in past and more recent studies for relapsed AML patients: the ECOG-ACRIN experience. Am J Hematol. 2018; 10:1002. https://doi.org/10.1002/ajh.25162. [PubMed]

10. Breems DA, Van Putten WL, Huijgens PC, Ossenkoppele GJ, Verhoef GE, Verdonck LF, Vellenga E, De Greef GE, Jacky E, Van der Lelie J, Boogaerts MA, Löwenberg B. Prognostic index for adult patients with acute myeloid leukemia in first relapse. J Clin Oncol. 2005; 23:1969-78. https://doi.org/10.1200/JCO.2005.06.027. [PubMed]

11. Perl AE, Martinelli G, Cortes JE, Neubauer A, Berman E, Paolini S, Montesinos P, Baer MR, Larson RA, Ustun C, Fabbiano F, Erba HP, Di Stasi A, et al. Gilteritinib or Chemotherapy for Relapsed or Refractory FLT3-Mutated AML. N Engl J Med. 2019; 381:1728-40. https://doi. org/10.1056/NEJMoa1902688. [PubMed]

12. DiNardo CD, Stein EM, de Botton S, Roboz GJ, Altman JK, Mims AS, Swords R, Collins RH, Mannis GN, Pollyea DA, Donnellan W, Fathi AT, Pigneux A, et al. Durable remissions with ivosidenib in IDH1-mutated relapsed or refractory AML. N Engl J Med. 2018; 378:2386-98. https:// doi.org/10.1056/NEJMoa1716984. [PubMed]

13. Stein EM, DiNardo CD, Fathi AT, Pollyea DA, Stone RM, Altman JK, Roboz GJ, Patel MR, Collins R, Flinn IW, Sekeres MA, Stein AS, Kantarjian HM, et al. Molecular remission and response patterns in patients with mutantIDH2 acute myeloid leukemia treated with enasidenib. Blood. 2019; 133:676-87. https://doi.org/10.1182/blood2018-08-869008. [PubMed]
14. Herzig RH, Lazarus HM, Wolff SN, Phillips GL, Herzig GP. High-dose cytosine arabinoside therapy with and without anthracycline antibiotics for remission reinduction of acute nonlymphoblastic leukemia. J Clin Oncol. 1985; 3:992-97. https://doi.org/10.1200/JCO.1985.3.7.992. [PubMed]

15. Spadea A, Petti MC, Fazi P, Vegna ML, Arcese W, Avvisati G, Aloe Spiriti MA, Latagliata R, Meloni G, Testi AM. Mitoxantrone, etoposide and intermediate-dose ara-C (MEC): an effective regimen for poor risk acute myeloid leukemia. Leukemia. 1993; 7:549-52. https://doi. org/10.3109/10428199209058667. [PubMed]

16. Estey E, Plunkett W, Gandhi V, Rios MB, Kantarjian $\mathrm{H}$, Keating MJ. Fludarabine and arabinosylcytosine therapy of refractory and relapsed acute myelogenous leukemia. Leuk Lymphoma. 1993; 9:343-50. https://doi. org/10.3109/10428199309148532. [PubMed]

17. Vogler WR, McCarley DL, Stagg M, Bartolucci AA, Moore J, Martelo O, Omura GA. A phase III trial of high-dose cytosine arabinoside with or without etoposide in relapsed and refractory acute myelogenous leukemia. A southeastern cancer study group trial. Leukemia. 1994; 8:1847-53. https://doi.org/10.1007/978-3-642-77083-8_43. [PubMed]

18. Daenen S, Löwenberg B, Sonneveld P, van Putten WL, Verhoef G, Verdonck LF, van Veldhoven M, Huijgens PC. Efficacy of etoposide and mitoxantrone in patients with acute myelogenous leukemia refractory to standard induction therapy and intermediate-dose cytarabine with amsidine. Dutch hematology-oncology working group for adults (HOVON). Leukemia. 1994; 8:6-10. https://doi. org/10.1038/sj.leu.2401478. [PubMed]

19. Steinmetz HT, Schulz A, Staib P, Scheid C, Glasmacher A, Neufang A, Franklin J, Tesch H, Diehl V, Dias Wickramanayake P. Phase-II trial of idarubicin, fludarabine, cytosine arabinoside, and filgrastim (Ida-FLAG) for treatment of refractory, relapsed, and secondary AML. Ann Hematol. 1999; 78:418-25. https://doi.org/10.1007/ s002770050541. [PubMed]

20. Taksin AL, Legrand O, Raffoux E, de Revel T, Thomas X, Contentin N, Bouabdallah R, Pautas C, Turlure P, Reman O, Gardin C, Varet B, de Botton S, et al. High efficacy and safety profile of fractionated doses of mylotarg as induction therapy in patients with relapsed acute myeloblastic leukemia: a prospective study of the alfa group. Leukemia. 2007; 21:66-71. https://doi.org/10.1038/sj.leu.2404434. [PubMed]

21. Giles F, Vey N, DeAngelo D, Seiter K, Stock W, Stuart R, Boskovic D, Pigneux A, Tallman M, Brandwein J, Kell J, Robak T, Staib P, et al. Phase 3 randomized, placebo-controlled, double-blind study of high-dose continuous infusion cytarabine alone or with laromustine (VNP40101M) in patients with acute myeloid leukemia in first relapse. Blood. 2009; 114:4027-33. https://doi. org/10.1182/blood-2009-06-229351. [PubMed]

22. Becker PS, Kantarjian HM, Appelbaum FR, Petersdorf SH, Storer B, Pierce S, Shan J, Hendrie PC, Pagel JM, 
Shustov AR, Stirewalt DL, Faderl S, Harrington E, Estey EH. Clofarabine with high dose cytarabine and granulocyte colony-stimulating factor (G-CSF) priming for relapsed and refractory acute myeloid leukaemia. Br J Haematol. 2011; 155:182-89. https://doi.org/10.1111/j.13652141.2011.08831.x. [PubMed]

23. Faderl S, Wetzler M, Rizzieri D, Schiller G, Jagasia M, Stuart R, Ganguly S, Avigan D, Craig M, Collins R, Maris M, Kovacsovics T, Goldberg S, et al. Clofarabine plus cytarabine compared with cytarabine alone in older patients with relapsed or refractory acute myelogenous leukemia: results from the CLASSIC I trial. J Clin Oncol. 2012; 30:2492-99. https://doi.org/10.1200/JCO.2011.37.9743. [PubMed]

24. Hütter-Krönke ML, Benner A, Döhner K, Krauter J, Weber D, Moessner M, Köhne CH, Horst HA, Schmidt-Wolf IG, Rummel M, Götze K, Koller E, Petzer AL, et al. Salvage therapy with high-dose cytarabine and mitoxantrone in combination with all-trans retinoic acid and gemtuzumab ozogamicin in acute myeloid leukemia refractory to first induction therapy. Haematologica. 2016; 101:839-45. https://doi.org/10.3324/haematol.2015.141622. [PubMed]

25. Megías-Vericat JE, Martínez-Cuadrón D, Sanz MÁ, Montesinos P. Salvage regimens using conventional chemotherapy agents for relapsed/refractory adult AML patients: a systematic literature review. Ann Hematol. 2018; 97:1115-53. https://doi.org/10.1007/s00277-018-3304-y. [PubMed]

26. MacCallum PK, Davis CL, Rohatiner AZ, Lim J, Gupta RK, Whelan JS, Price CG, Evans ML, Amess JA, Leahy M. Mitoxantrone and cytosine arabinoside as treatment for acute myelogenous leukemia (AML) at first recurrence. Leukemia. 1993; 7:1496-99. https://doi.org/10.1007/ bf01696230. [PubMed]

27. Karanes C, Kopecky KJ, Head DR, Grever MR, Hynes HE, Kraut EH, Vial RH, Lichtin A, Nand S, Samlowski WE, Appelbaum FR. A phase III comparison of high dose ARA-C (HIDAC) versus HIDAC plus mitoxantrone in the treatment of first relapsed or refractory acute myeloid leukemia southwest oncology group study. Leuk Res. 1999; 23:787-94. https://doi.org/10.1016/s0145-2126(99)000879. [PubMed]

28. Raanani P, Shpilberg O, Gillis S, Avigdor A, Hardan I, Berkowicz M, Sofer O, Lossos I, Chetrit A, Ben-Yehuda D, Ben-Bassat I. Salvage therapy of refractory and relapsed acute leukemia with high dose mitoxantrone and high dose cytarabine. Leuk Res. 1999; 23:695-700. https://doi. org/10.1016/s0145-2126(99)00078-8. [PubMed]

29. Papaemmanuil E, Gerstung M, Bullinger L, Gaidzik VI, Paschka P, Roberts ND, Potter NE, Heuser M, Thol F, Bolli N, Gundem G, Van Loo P, Martincorena I, et al. Genomic classification and prognosis in acute myeloid leukemia. N Engl J Med. 2016; 374:2209-21. https://doi.org/10.1056/ NEJMoa1516192. [PubMed]

30. Patel JP, Gönen M, Figueroa ME, Fernandez H, Sun Z, Racevskis J, Van Vlierberghe P, Dolgalev I, Thomas
S, Aminova O, Huberman K, Cheng J, Viale A, et al. Prognostic relevance of integrated genetic profiling in acute myeloid leukemia. N Engl J Med. 2012; 366:1079-89. https://doi.org/10.1056/NEJMoa1112304. [PubMed]

31. Jongen-Lavrencic M, Grob T, Hanekamp D, Kavelaars FG, Al Hinai A, Zeilemaker A, Erpelinck-Verschueren CA, Gradowska PL, Meijer R, Cloos J, Biemond BJ, Graux C, van Marwijk Kooy M, et al. Molecular minimal residual disease in acute myeloid leukemia. N Engl J Med. 2018; 378:1189-99. https://doi.org/10.1056/NEJMoa1716863. [PubMed]

32. Ravandi F, Ritchie EK, Sayar H, Lancet JE, Craig MD, Vey N, Strickland SA, Schiller GJ, Jabbour E, Erba HP, Pigneux A, Horst HA, Recher C, et al. Vosaroxin plus cytarabine versus placebo plus cytarabine in patients with first relapsed or refractory acute myeloid leukaemia (VALOR): a randomised, controlled, double-blind, multinational, phase 3 study. Lancet Oncol. 2015; 16:1025-36. https://doi. org/10.1016/S1470-2045(15)00201-6. [PubMed]

33. Roboz GJ, Rosenblat T, Arellano M, Gobbi M, Altman JK, Montesinos P, O'Connell C, Solomon SR, Pigneux A, Vey N, Hills R, Jacobsen TF, Gianella-Borradori A, et al. International randomized phase III study of elacytarabine versus investigator choice in patients with relapsed/refractory acute myeloid leukemia. J Clin Oncol. 2014; 32:1919-26. https://doi.org/10.1200/JCO.2013.52.8562. [PubMed]

34. Ivanoff S, Gruson B, Chantepie SP, Lemasle E, Merlusca L, Harrivel V, Charbonnier A, Votte P, Royer B, Marolleau JP. 5-azacytidine treatment for relapsed or refractory acute myeloid leukemia after intensive chemotherapy. Am J Hematol. 2013; 88:601-05. https://doi.org/10.1002/ ajh.23464. [PubMed]

35. Jackson G, Taylor P, Smith GM, Marcus R, Smith A, Chu P, Littlewood TJ, Duncombe A, Hutchinson M, Mehta AB, Johnson SA, Carey P, MacKie MJ, et al. A multicentre, open, non-comparative phase II study of a combination of fludarabine phosphate, cytarabine and granulocyte colonystimulating factor in relapsed and refractory acute myeloid leukaemia and de novo refractory anaemia with excess of blasts in transformation. Br J Haematol. 2001; 112:127-37. https://doi.org/10.1046/j.1365-2141.2001.02551.x. [PubMed]

36. Marr KA, Seidel K, Slavin MA, Bowden RA, Schoch HG, Flowers ME, Corey L, Boeckh M. Prolonged fluconazole prophylaxis is associated with persistent protection against candidiasis-related death in allogeneic marrow transplant recipients: long-term follow-up of a randomized, placebo-controlled trial. Blood. 2000; 96:2055-61. https://doi.org/10.1182/blood.v96.6.2055. h8002055_2055_2061. [PubMed]

37. Cornely OA, Maertens J, Winston DJ, Perfect J, Ullmann AJ, Walsh TJ, Helfgott D, Holowiecki J, Stockelberg D, Goh YT, Petrini M, Hardalo C, Suresh R, Angulo-Gonzalez D. Posaconazole vs. Fluconazole or itraconazole prophylaxis in patients with neutropenia. N Engl J Med. 2007; 356:348-59. https://doi.org/10.1056/NEJMoa061094. [PubMed] 
38. Derolf AR, Kristinsson SY, Andersson TM, Landgren O, Dickman PW, Björkholm M. Improved patient survival for acute myeloid leukemia: a population-based study of 9729 patients diagnosed in Sweden between 1973 and 2005. Blood. 2009; 113:3666-72. https://doi.org/10.1182/blood2008-09-179341. [PubMed]

39. Giri S, Pathak R, Aryal MR, Karmacharya P, Bhatt VR, Martin MG. Impact of hospital volume on outcomes of patients undergoing chemotherapy for acute myeloid leukemia: a matched cohort study. Blood. 2015; 125:335960. https://doi.org/10.1182/blood-2015-01-625764. [PubMed]

40. Canaani J, Beohou E, Labopin M, Ghavamzadeh A, Beelen D, Hamladji RM, Niederwieser D, Volin L, Markiewicz M, Arnold R, Mufti G, Ehninger G, Socié G, et al. Trends in patient outcome over the past two decades following allogeneic stem cell transplantation for acute myeloid leukaemia: an ALWP/EBMT analysis. J Intern Med. 2019; 285:407-18. https://doi.org/10.1111/joim.12854. [PubMed]

41. Kurosawa S, Yamaguchi T, Miyawaki S, Uchida N, Sakura T, Kanamori H, Usuki K, Yamashita T, Okoshi Y, Shibayama H, Nakamae H, Mawatari M, Hatanaka K, et al. Prognostic factors and outcomes of adult patients with acute myeloid leukemia after first relapse. Haematologica. 2010; 95:1857-64. https://doi.org/10.3324/haematol.2010.027516. [PubMed]

42. Chevallier P, Labopin M, Turlure P, Prebet T, Pigneux A, Hunault M, Filanovsky K, Cornillet-Lefebvre P, Luquet I, Lode L, Richebourg S, Blanchet O, Gachard N, et al. A new leukemia prognostic scoring system for refractory/relapsed adult acute myelogeneous leukaemia patients: a GOELAMS study. Leukemia. 2011; 25:939-44. https://doi.org/10.1038/ leu.2011.25. [PubMed]

43. Bergua JM, Montesinos P, Martinez-Cuadrón D, FernándezAbellán P, Serrano J, Sayas MJ, Prieto-Fernandez J, García R, García-Huerta AJ, Barrios M, Benavente C, PérezEncinas M, Simiele A, et al, and PETHEMA group. A prognostic model for survival after salvage treatment with FLAG-ida +/- gemtuzumab-ozogamicine in adult patients with refractory/relapsed acute myeloid leukaemia. Br J Haematol. 2016; 174:700-10. https://doi.org/10.1111/ bjh.14107. [PubMed]

44. Burnett AK, Goldstone A, Hills RK, Milligan D, Prentice A, Yin J, Wheatley K, Hunter A, Russell N. Curability of patients with acute myeloid leukemia who did not undergo transplantation in first remission. J Clin Oncol. 2013; 31:1293-301. https://doi.org/10.1200/JCO.2011.40.5977. [PubMed]

45. Ley TJ, Miller C, Ding L, Raphael BJ, Mungall AJ, Robertson A, Hoadley K, Triche TJ Jr, Laird PW, Baty JD, Fulton LL, Fulton R, Heath SE, et al, and Cancer Genome Atlas Research Network. Genomic and epigenomic landscapes of adult de novo acute myeloid leukemia. N Engl J Med. 2013; 368:2059-74. https://doi.org/10.1056/ NEJMoa1301689. [PubMed]
46. Ding L, Ley TJ, Larson DE, Miller CA, Koboldt DC, Welch JS, Ritchey JK, Young MA, Lamprecht T, McLellan MD, McMichael JF, Wallis JW, Lu C, et al. Clonal evolution in relapsed acute myeloid leukaemia revealed by wholegenome sequencing. Nature. 2012; 481:506-10. https://doi. org/10.1038/nature10738. [PubMed]

47. Barbosa K, Li S, Adams PD, Deshpande AJ. The role of TP53 in acute myeloid leukemia: challenges and opportunities. Genes Chromosomes Cancer. 2019; 58:875-88. https://doi. org/10.1002/gcc.22796. [PubMed]

48. McMahon CM, Ferng T, Canaani J, Wang ES, Morrissette JJ, Eastburn DJ, Pellegrino M, Durruthy-Durruthy R, Watt CD, Asthana S, Lasater EA, DeFilippis R, Peretz CA, et al. Clonal selection with RAS pathway activation mediates secondary clinical resistance to selective FLT3 inhibition in acute myeloid leukemia. Cancer Discov. 2019; 9:1050-63. https://doi.org/10.1158/2159-8290.CD-18-1453. [PubMed]

49. Zhang H, Savage S, Schultz AR, Bottomly D, White L, Segerdell E, Wilmot B, McWeeney SK, Eide CA, Nechiporuk T, Carlos A, Henson R, Lin C, et al. Clinical resistance to crenolanib in acute myeloid leukemia due to diverse molecular mechanisms. Nat Commun. 2019; 10:244. https://doi.org/10.1038/s41467-018-08263-x. [PubMed]

50. Intlekofer AM, Shih AH, Wang B, Nazir A, Rustenburg AS, Albanese SK, Patel M, Famulare C, Correa FM, Takemoto N, Durani V, Liu H, Taylor J, et al. Acquired resistance to IDH inhibition through trans or cis dimerinterface mutations. Nature. 2018; 559:125-29. https://doi. org/10.1038/s41586-018-0251-7. [PubMed]

51. Tyner JW, Tognon CE, Bottomly D, Wilmot B, Kurtz SE, Savage SL, Long N, Schultz AR, Traer E, Abel M, Agarwal A, Blucher A, Borate U, et al. Functional genomic landscape of acute myeloid leukaemia. Nature. 2018; 562:526-31. https://doi.org/10.1038/s41586-018-0623-z. [PubMed]

52. Pardee TS, Anderson RG, Pladna KM, Isom S, Ghiraldeli LP, Miller LD, Chou JW, Jin G, Zhang W, Ellis LR, Berenzon D, Howard DS, Hurd DD, et al. A phase I study of CPI-613 in combination with high-dose cytarabine and mitoxantrone for relapsed or refractory acute myeloid leukemia. Clin Cancer Res. 2018; 24:2060-73. https://doi. org/10.1158/1078-0432.CCR-17-2282. [PubMed]

53. Ravandi F. Primary refractory acute myeloid leukaemia - in search of better definitions and therapies. Br J Haematol. 2011; 155:413-19. https://doi.org/10.1111/j.1365-2141. 2011.08869.x. [PubMed]

54. Cheson BD, Bennett JM, Kopecky KJ, Büchner T, Willman CL, Estey EH, Schiffer CA, Doehner H, Tallman MS, Lister TA, Lo-Coco F, Willemze R, Biondi A, et al, International Working Group for Diagnosis, Standardization of Response Criteria, Treatment Outcomes, and Reporting Standards for Therapeutic Trials in Acute Myeloid Leukemia. Revised recommendations of the International Working Group for Diagnosis, Standardization of Response Criteria, Treatment Outcomes, and Reporting Standards for Therapeutic Trials in Acute Myeloid Leukemia. J Clin Oncol. 2003; 
21:4642-49. https://doi.org/10.1200/JCO.2003.04.036. [PubMed]

55. Grimwade D, Hills RK, Moorman AV, Walker H, Chatters S, Goldstone AH, Wheatley K, Harrison CJ, Burnett AK, and National Cancer Research Institute Adult Leukaemia Working Group. Refinement of cytogenetic classification in acute myeloid leukemia: determination of prognostic significance of rare recurring chromosomal abnormalities among 5876 younger adult patients treated in the United Kingdom medical research council trials. Blood. 2010; 116:354-65. https://doi.org/10.1182/blood-2009-11-254441. [PubMed] 